\title{
SELECTING THE FIELD HOSPITAL PLACE FOR DISASTERS: A CASE STUDY IN ISTANBUL
}

\author{
Nazanin Vafaei \\ Department of Industrial Engineering \\ Istanbul Technical University \\ Istanbul, Turkey \\ E-mail: vafaei@itu.edu.tr \\ Basar Oztaysi \\ Department of Industrial Engineering \\ Istanbul Technical University \\ Istanbul, Turkey \\ E-mail: oztaysib@itu.edu.tr
}

\begin{abstract}
Increasing population growth and lack of enough medicine care within disaster such as volcanic eruption, typhoon, tropical cyclone, tornado an earthquake, a landslide or war is the most important problem for the disaster managers and metropolitans. Importance of disaster preparedness, the effects of disasters in previous years, Importance of Medical services in case of emergency persuade us to select a proper place for emergency field hospitals. In the emergency cases we can use Multi-Criteria Decision Making (MCDM) and Geographical Information System (GIS) together for having better evaluating. So, we use Multi-Criteria Decision Making process that combines Geographical Information System (GIS) analysis with the Analytical Hierarchy Process (AHP), and use this process to determine the optimum site for field hospital in the Istanbul urban area. We use some criteria such as Distance from Arterial Routes, Travel Time area to access existing hospitals; Environmental pollution, Population Density, Time of Operate, and Capacity of Beds.
\end{abstract}

Keywords: GIS, Geographical Information System, Analytical Hierarchy Process, AHP, Emergency. 


\section{Introduction}

Increasing population growth and lack of enough medicine care within disaster such as volcanic eruption, typhoon, tropical cyclone, tornado an earthquake, a landslide or war is the most important problem for the disaster managers and metropolitans. So, we use MultiCriteria Decision Analysis process that combines Geographical Information System (GIS) analysis with the Analytical Hierarchy Process (AHP), and use this process to determine the optimum site for field hospital in the Istanbul urban area. We use some criteria such as Distance from Arterial Routes, Travel Time area to access existing hospitals; Environmental pollution, Population Density, Time to Operate, and Capacity of Beds.

\section{Literature Review}

\section{GIS and site selection:}

During the last few years, GIS has been used as a system for management, manipulation, representation and analysis of geospatial data to facilitate and cut down costs in the site selection process. The goal of a site selection exercise is to find the optimum location that satisfies a number of predefined criteria (Healey and Ilbery, 1990). The process of site selection typically involves two main phases: screening (identifying a limited number of candidate sites from a broad geographical area given a range of selection factors) and evaluation (in-depth examination of alternatives to determine the most suitable site) (Chang et al., 2008). A multitude of sometimes contradictory factors are involved in both phases. In such a situation, a number of tools are available to determine the optimum site (Witlox, 2005). These tools include Expert Systems (ES) for well-defined and structured problems and Decision Support System (DSS) for ill-structured problems or their combination. But, combining a GIS with MCDM techniques can facilitate site selection in cases where the problem is ill-structured or semi-structured, meaning that decision-makers do not have complete and reliable information regarding specifications, alternatives and outcomes (Zucca et al., 2008; Chang et al., 2008; Witlox, 2005). Traditional methods of GIS site selection are based on the transformation of effective layers into a classified map, for example using a Boolean model (Louviere et al., 2000) or Index Overlay operations (Nikolakaki, 2004; Alesheikh et al., 2008; Alesheikh and Sadeghi Naeeni Fard, 2007; Kallali et al., 2007).

\section{Analytical Hierarchy Process (AHP):}

The AHP proposed by Saaty (1980) is a flexible, quantitative method for selecting among alternatives based on their relative performance with respect to one or more criteria of interest (Boroushaki and Malczewski, 2008; Linkov et al., 2007). AHP resolves complex decisions by structuring the alternatives into a hierarchical framework. The hierarchy is constructed through pairwise comparisons of individual judgments, rather than attempting to prioritize the entire list of decisions and criteria simultaneously (Saaty, 1980).

The AHP procedure generally involves six steps (Lee et al., 2008; Hosseinali and Alesheikh, 2008):

1) Define the unstructured problem, stating clearly its objectives and outcomes.

International Symposium of

2

the Analytic Hierarchy

Process
Washington, D. C. June 29 - July 2, 2014 
IJAHP Article: Mu, Saaty/A Style Guide for Paper Proposals To Be Submitted to the International Symposium of the Analytic Hierarchy Process 2014, Washington D.C., U.S.A.

2) Decompose the complex problem into decision elements (detailed criteria and alternatives).

3) Employ pairwise comparisons among decision elements to form comparison matrices. Saaty (1980) describes a suitable measurement scale for the pairwise comparisons, where verbal judgments are expressed by a degree of preference: equally preferred $=1$, moderately preferred $=3$, strongly preferred $=5$, very strongly preferred $=7$ and extremely preferred $=9$. The numbers 2, 4, 6 and 8 are used to distinguish similar alternatives (Brent et al., 2007). Reciprocals of these numbers are used to express the inverse relationship.

4) Use the eigenvalue method (or some other method) to estimate the relative weights of the decision elements.

5) Calculate the consistency properties of the matrices to ensure that the judgments of decision-makers are consistent. The consistency index (CI) is calculated as:

$$
\mathbf{C I}=\left(\lambda_{\max }-\mathbf{n}\right) /(\mathbf{n}-\mathbf{1})
$$

Where $\lambda_{\max }$ is the biggest eigenvalue of the pairwise comparison matrix. The consistency index of a randomly generated reciprocal matrix is called the random index (RI). The average RI values for matrices of orders 1-15 have already been generated for a sample size of 100 (Brent et al., 2007). The last ratio that has to be calculated is the CR (Consistency Ratio). If the CR is less than 0.1, the judgments are consistent and the derived weights can be used. The formula for calculating CR is simply:

\section{$\mathbf{C R}=\mathbf{C I} / \mathbf{R I}$}

6) Aggregate the weighted decision elements to obtain an overall rating for the alternatives. An overall priority ranking of the decision alternatives can be obtained by combining the criterion priorities and priorities of each decision alternative relative to each criterion. (Chen et al. 2006).

\section{Location Selection using MCDM and GIS: Emergency cases:}

In the emergency cases we can use MCDM and GIS together for having better evaluating. For selecting fire station in Istanbul (Erden and Coskun, 2010) used AHP for calculating weights and pairwise matrices, then they used GIS for evaluating alternatives by using the AHP results. In addition, MCDM and GIS is used for selection optimum site for building hospital (Vahidnia, Alesheikh, Alimohammadi, 2009) with the Fuzzy Analytical Hierarchy Process (FAHP). They define alternatives and survived them with GIS and then used FAHP for defining the weight of criteria and pairwise matrices in the fuzzy. In this study we want to find optimum location for field hospital in the disaster. First, we define criteria and alternatives, then use GIS for showing alternatives and their locations in the maps and have primary evaluation and results with GIS, in the next step, we define the weight of criteria and pairwise matrices, then we use them and GIS results as inputs for AHP for evaluating alternative to finding best place for installing field hospital. 


\section{Hypotheses/Objectives}

The objective of the study is to select a location for field hospital in Besiktas in case of disasters (Figure1). For installing field hospital, parks are the best places in the city because they have enough space for installing tents and giving emergency services to the patients that are threatened by disaster.

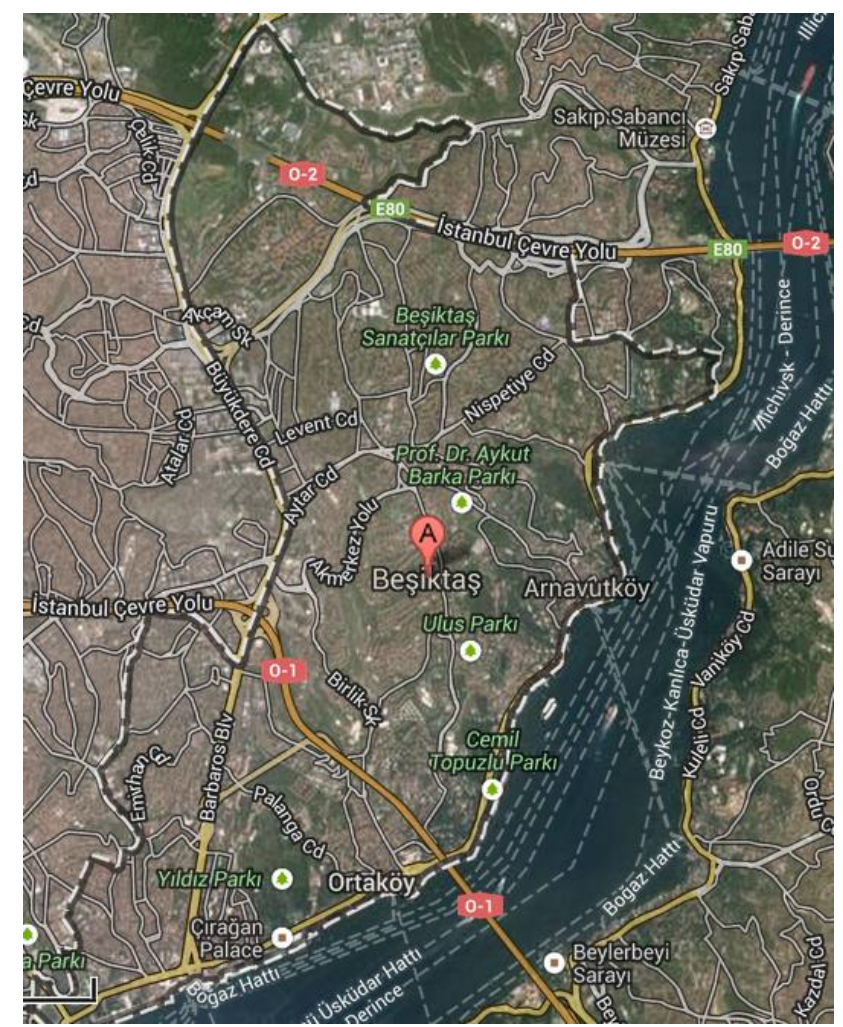

Figure 1. Besiktas

\section{Alternatives:}

We selected Besiktas district of Istanbul, because it is one of the most important centers in the Istanbul and the population density is high in this district. We evaluate our alternatives that are listed as below with the AHP and GIS:

1-Beşiktaş Sanatçılar Park

2-Prof. Dr. Aykut Barka Park

3-Ulus Park

4-Cemil Topuzlu Park

5-Y1ldız Park 


\section{Decision Model:}

For evaluating alternatives for field hospital in the case of Besiktas we use some criteria such as Distance from Arterial Routes, Travel Time area to access existing hospitals, Environmental Pollution, Population Density, Time to Operate, Capacity of Beds. We try to find optimum of each criteria, for example for Distance from Arterial Routes we prefer to have minimum distance or for Travel Time area to access existing hospitals we need to have minimum time of accessibility and for population density we prefer to have maximum density of population for selecting best alternatives in case of field hospital in Besiktas.

\section{Research Design/Methodology}

First, we obtain our data such as Distance from Arterial Routes, Travel Time area to access existing hospitals; Environmental pollution, and Population Density and use GIS method for analyzing them. Then, we use the results of GIS and add some other criteria such as Time to Operate, and Capacity of Beds for using the method of AHP. In AHP method we calculate CI and comparison matrices and compare the results that are obtained from AHP method and combine these results with the GIS results. Finally, we define the rank of criteria and sort them by their priority.

The process of our study is shown in the following (figure2):

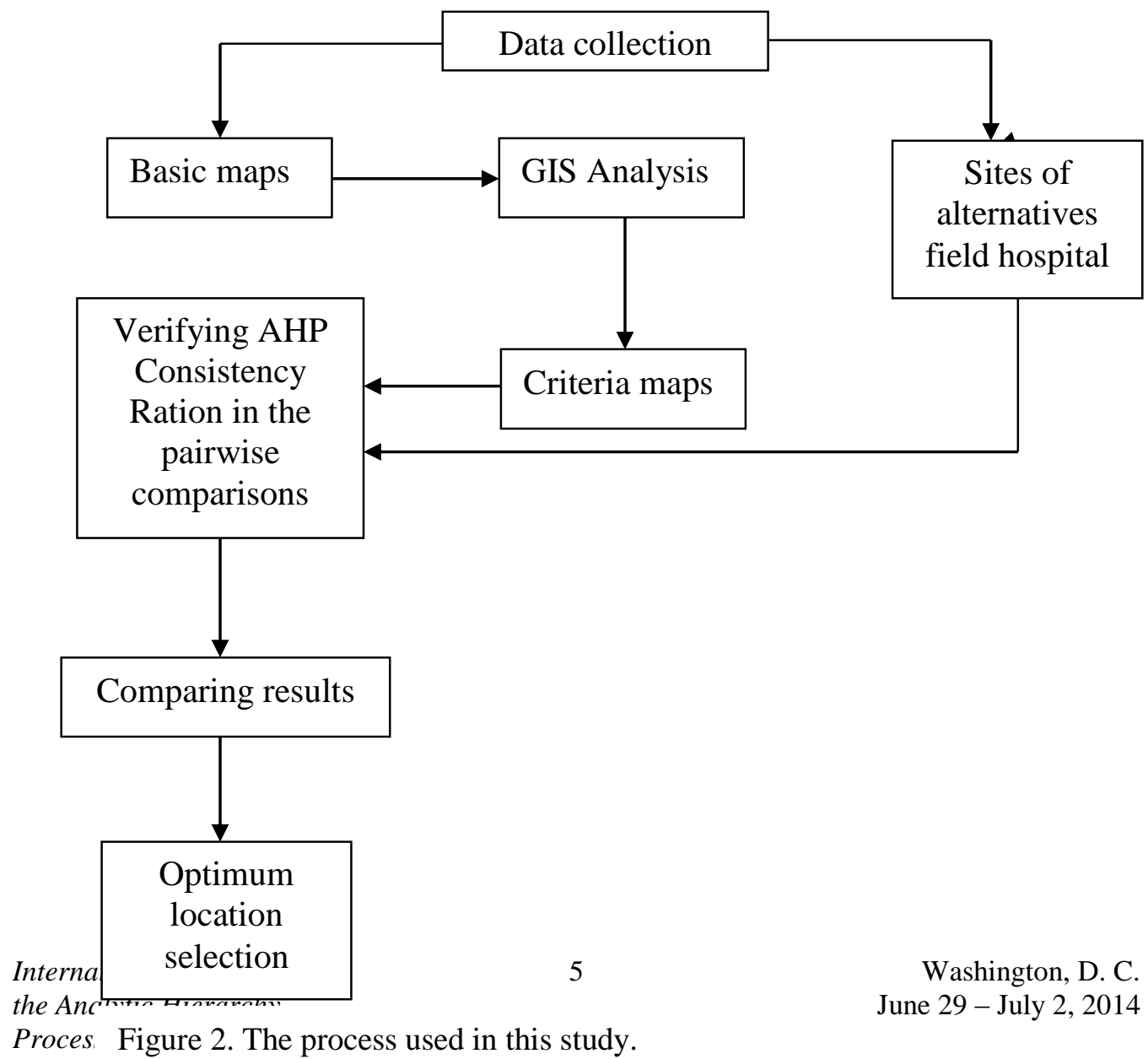


IJAHP Article: Mu, Saaty/A Style Guide for Paper Proposals To Be Submitted to the International Symposium of the Analytic Hierarchy Process 2014, Washington D.C., U.S.A.

\section{Data/Model Analysis}

The following figure (Figure. 7) depicts the hierarchical structure of the problem. The possible relationships between sites (alternatives, numbered 1 through 5) and criteria (objectives). The overall goal (top) is to discover the optimal site for field hospital; the information contained in the maps (Distance from Arterial Routes, Travel Time area to access existing hospitals; Environmental pollution, and Population Density) combined with other information (Time to Operate, and Capacity of Beds) and define the objectives.

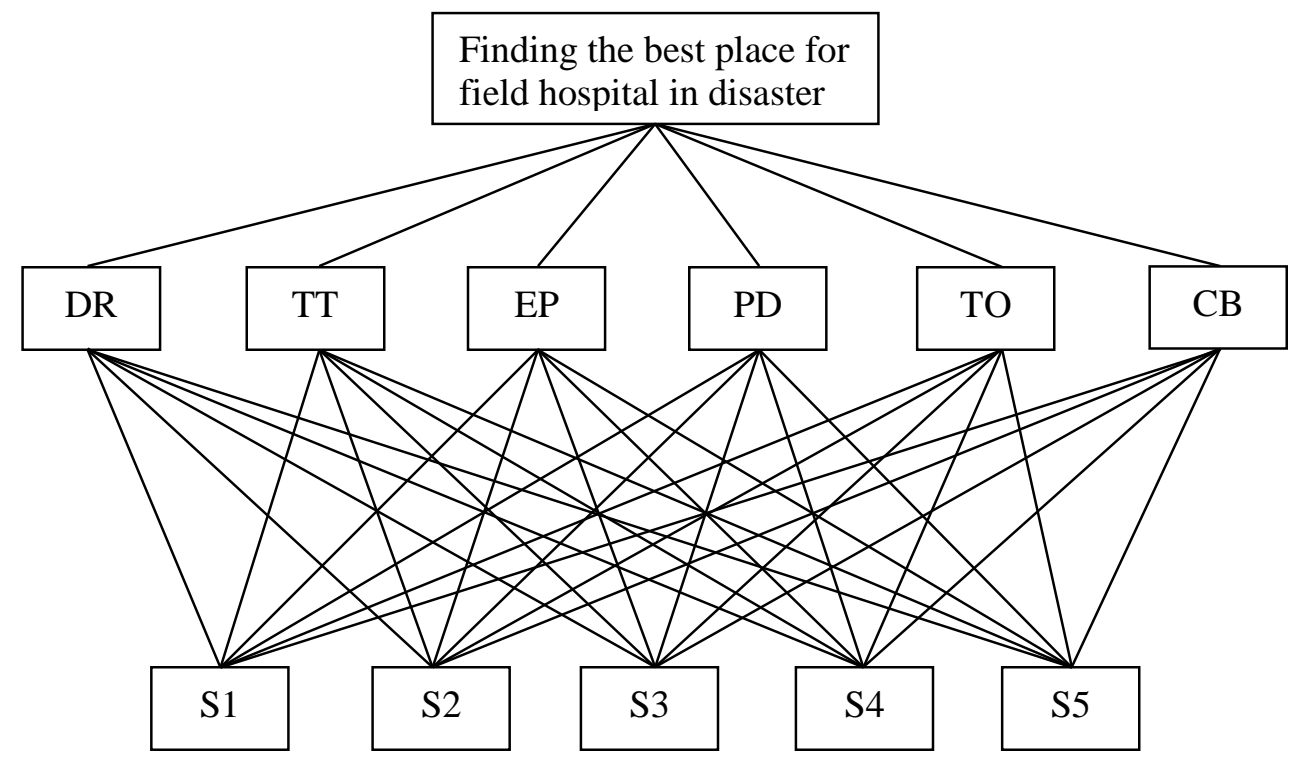

DR: Distance from Arterial Routes

TT: Travel Time area to access existing hospitals

EP: Environmental Pollution

PD: Population Density

TO: Time to Operate

CB: Capacity of Beds

S: Sites

Figure. 7. The hierarchical structure of decision-making. 
In the first phase of the study, three experts are asked to make pairwise comparisons about the evaluation criteria. The evaluations are presented in Table 1.

\begin{tabular}{|c|c|c|c|c|c|c|c|c|c|c|c|c|c|c|c|c|c|c|}
\hline & \multicolumn{3}{|c|}{$\overline{\mathrm{DR}}$} & \multicolumn{3}{|c|}{ TT } & \multicolumn{3}{|c|}{$\overline{E P}$} & \multicolumn{3}{|c|}{ PD } & \multicolumn{3}{|c|}{$\mathrm{TO}$} & \multicolumn{3}{|c|}{$\mathrm{CB}$} \\
\hline & $\begin{array}{c}\operatorname{Exp} \\
1\end{array}$ & $\mathrm{Ex}_{2}$ & $\begin{array}{c}\text { Exp } \\
3\end{array}$ & $\begin{array}{c}\operatorname{Exp} \\
1\end{array}$ & $\begin{array}{c}\operatorname{Exp} \\
2\end{array}$ & $\begin{array}{c}\operatorname{Exp} \\
3\end{array}$ & $\begin{array}{c}\text { Exp } \\
1\end{array}$ & $\begin{array}{c}\text { Exp } \\
2\end{array}$ & $\begin{array}{c}\text { Exp } \\
3\end{array}$ & $\begin{array}{c}\operatorname{Exp} \\
1\end{array}$ & $\begin{array}{c}\operatorname{Exp} \\
2\end{array}$ & $\begin{array}{c}\text { Exp } \\
3\end{array}$ & $\begin{array}{c}\text { Exp } \\
1\end{array}$ & $\begin{array}{c}\text { Exp } \\
2\end{array}$ & $\begin{array}{c}\text { Exp } \\
3\end{array}$ & $\begin{array}{c}\text { Exp } \\
1\end{array}$ & $\begin{array}{c}\operatorname{Exp} \\
2\end{array}$ & $\begin{array}{c}\text { Exp } \\
3\end{array}$ \\
\hline DR & EI & EI & EI & $1 / \mathrm{WI}$ & EI & EI & $1 / \mathrm{VI}$ & 1/AI & $1 / \mathrm{SI}$ & $1 / \mathrm{AI}$ & 1/AI & $1 / \mathrm{VI}$ & $1 / \mathrm{SI}$ & $1 / \mathrm{VI}$ & $1 / \mathrm{SI}$ & $1 / \mathrm{WI}$ & $1 / \mathrm{SI}$ & $1 / \mathrm{SI}$ \\
\hline TT & WI & EI & EI & EI & EI & EI & $1 / \mathrm{SI}$ & $1 / \mathrm{WI}$ & $1 / \mathrm{VI}$ & $1 / \mathrm{SI}$ & $1 / \mathrm{VI}$ & $1 / \mathrm{VI}$ & $1 / \mathrm{SI}$ & $1 / \mathrm{SI}$ & $1 / \mathrm{WI}$ & EI & $1 / \mathrm{WI}$ & $1 / \mathrm{WI}$ \\
\hline EP & VI & AI & SI & SI & WI & VI & EI & EI & EI & $1 / \mathrm{SI}$ & $1 / \mathrm{WI}$ & $1 / \mathrm{WI}$ & WI & WI & EI & VI & SI & SI \\
\hline PD & AI & AI & VI & SI & VI & VI & $1 / \mathrm{SI}$ & WI & WI & EI & EI & EI & VI & VI & SI & AI & VI & VI \\
\hline TO & SI & VI & SI & SI & SI & WI & $1 / \mathrm{WI}$ & $1 / \mathrm{WI}$ & EI & $1 / \mathrm{VI}$ & $1 / \mathrm{VI}$ & $1 / \mathrm{SI}$ & EI & EI & EI & EI & EI & WI \\
\hline $\mathrm{CB}$ & WI & SI & SI & EI & WI & WI & $1 / \mathrm{VI}$ & $1 / \mathrm{SI}$ & $1 / \mathrm{SI}$ & $1 / \mathrm{AI}$ & $1 / \mathrm{VI}$ & $1 / \mathrm{VI}$ & EI & EI & $1 / \mathrm{WI}$ & EI & EI & EI \\
\hline
\end{tabular}

Table 1. Expert Evaluations about criteria

For each expert, the consistency checks are done. The consistency ratio of each expert evaluations are $0.06,0.09$, and 0.08 respectively. Since the values are under the threshold value $(0.10)$ we continue our calculations. The numerical representation of the evaluations are shown in Table 2.

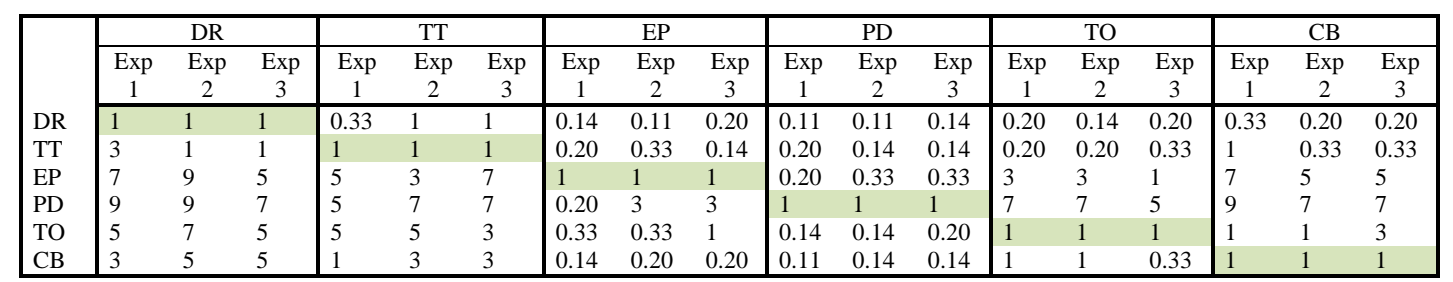

Table 2. Expert Evaluations about criteria

In order to find the aggregated evaluations, the geometric means of expert evaluations are calculated. The aggregated evaluations and the calculated weights of the criteria are given in Table 3.

\begin{tabular}{l|lllllll} 
& DR & TT & EP & PD & TO & CB & Weights \\
\hline DR & 1.00 & 0.69 & 0.15 & 0.12 & 0.18 & 0.24 & 0.036 \\
TT & 1.44 & 1.00 & 0.21 & 0.16 & 0.24 & 0.48 & 0.052 \\
EP & 6.80 & 4.72 & 1.00 & 0.28 & 2.08 & 5.59 & 0.250 \\
PD & 8.28 & 6.26 & 1.22 & 1.00 & 6.26 & 7.61 & 0.435 \\
TO & 5.59 & 4.22 & 0.48 & 0.16 & 1.00 & 1.44 & 0.141 \\
CB & 4.22 & 2.08 & 0.18 & 0.13 & 0.69 & 1.00 & 0.086
\end{tabular}

Table 3. Aggregated expert evaluations and the calculated weights of the criteria.

After determining the weights of the criteria, AHP scoring approach is used to determine the best alternative. To this end, the experts identified a scale that is composed of variables \{Very Bad, Bad, Medium, High, Very High\}. Table 4 shows the pairwise comparison of these variables. 


\begin{tabular}{c|ccccc} 
& VB & BD & ME & HI & VH \\
\hline VB & EI & $1 / \mathrm{WI}$ & $1 / \mathrm{SI}$ & $1 / \mathrm{VI}$ & $1 / \mathrm{AI}$ \\
BD & $\mathrm{WI}$ & $\mathrm{EI}$ & $1 / \mathrm{WI}$ & $1 / \mathrm{SI}$ & $1 / \mathrm{VI}$ \\
ME & $\mathrm{SI}$ & $\mathrm{WI}$ & $\mathrm{EI}$ & $1 / \mathrm{WI}$ & $1 / \mathrm{SI}$ \\
HI & $\mathrm{VI}$ & $\mathrm{SI}$ & $\mathrm{WI}$ & $\mathrm{EI}$ & $1 / \mathrm{WI}$ \\
VH & $\mathrm{AI}$ & $\mathrm{VI}$ & $\mathrm{SI}$ & $\mathrm{WI}$ & $\mathrm{EI}$ \\
\hline
\end{tabular}

Table 4. Expert evaluations about the evaluation scale

Based on the given pairwise comparisons, the weights of the variables are determined as follows:

\begin{tabular}{c|c} 
& Weights \\
\hline Very Bad (VB) & 0.070 \\
Bad (BD) & 0.135 \\
Medium (ME) & 0.266 \\
High (HI) & 0.517 \\
Very High (VH) & 1 \\
\hline
\end{tabular}

Table 5. The weights of the scale to be used in AHP Scoring

At the final step of the study, the alternatives are shown to the experts using a GIS software and they are asked to make evaluations about the alternatives. The Scale given in Table 5 is used for transforming the linguistic evaluations to numerical values. Table 6 gives the expert evaluations about the alternative field hospital locations with respect to the criteria.

\begin{tabular}{|c|c|c|c|c|c|c|c|c|c|}
\hline & \multicolumn{3}{|c|}{ DR } & \multicolumn{3}{|c|}{ TT } & \multicolumn{3}{|c|}{ EP } \\
\hline & Exp1 & Exp2 & Exp3 & Exp1 & Exp2 & Exp3 & Exp1 & Exp2 & Exp3 \\
\hline 1 & BD & $\mathrm{ME}$ & ME & ME & $\mathrm{HI}$ & $\mathrm{ME}$ & $\mathrm{HI}$ & ME & $\mathrm{ME}$ \\
\hline A2 & ME & ME & BD & $\mathrm{H}$ & $\mathrm{VH}$ & $\mathrm{HI}$ & $\mathrm{HI}$ & I & $\mathrm{ME}$ \\
\hline A & BD & BD & VB & & $\mathrm{Ml}$ & $\mathrm{ME}$ & AE & $\mathrm{ME}$ & $\mathrm{HI}$ \\
\hline A4 & 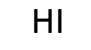 & $N$ & ME & $\mathrm{IE}$ & $\mathrm{ME}$ & $\mathrm{HI}$ & $\mathrm{H}$ & 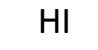 & $\mathrm{HI}$ \\
\hline \multirow[t]{3}{*}{$A$} & $\mathrm{VH}$ & $\mathrm{H}$ & $\mathrm{HI}$ & $E$ & 111 & $\mathrm{HI}$ & VH & $\mathrm{HI}$ & $\mathrm{VH}$ \\
\hline & \multicolumn{3}{|c|}{ PD } & \multicolumn{3}{|c|}{ TO } & \multicolumn{3}{|c|}{ CB } \\
\hline & Exp1 & Exp2 & Exp3 & Exp1 & Exp2 & Exp3 & Exp1 & Exp2 & Exp3 \\
\hline A1 & $\mathrm{HI}$ & $\mathrm{HI}$ & $\mathrm{VH}$ & $\mathrm{HI}$ & $\mathrm{ME}$ & $\mathrm{ME}$ & ME & $\mathrm{HI}$ & $\mathrm{HI}$ \\
\hline$A 2$ & $\mathrm{HI}$ & VH & $\mathrm{HI}$ & VH & ПI & $\mathrm{HI}$ & ME & $\mathrm{HI}$ & $\mathrm{ME}$ \\
\hline A3 & ME & BD & $\mathrm{ME}$ & 111 & $\mathrm{ME}$ & $\mathrm{ME}$ & VH & VH & $\mathrm{HI}$ \\
\hline A4 & BD & VB & BD & VH & ME & $\mathrm{HI}$ & ME & $\mathrm{ME}$ & $\mathrm{HI}$ \\
\hline |דנט & $\mathrm{ME}$ & $\mathrm{HI}$ & ME & VH & $\mathrm{HI}$ & HI & $\mathrm{VH}$ & $\mathrm{HI}$ & VH \\
\hline
\end{tabular}

Table 6. Expert evaluations about alternative field hospital locations

International Symposium of the Analytic Hierarchy

Process June 29 - July 2, 2014 
The evaluations given in Table 6 is aggregated using geometric means and presented in Table 7 with the criteria weights. In order to find the final scores of the alternatives, the aggregated evaluations are multiplied with the criteria weights and summed up. For example:

$$
\begin{gathered}
S 1=(0.036 * 0.212)+(0.052 * 0.332)+(0.25 * 0.332)+(0.435 * 0.644) \\
+(0.141 * 0.332)+(0.082 * 0.414)=0.471
\end{gathered}
$$

Last column of Table 7 represents the final scores of the alternatives.

\begin{tabular}{lccccccc} 
& DR & TT & EP & PD & TO & CB & Scores \\
\cline { 2 - 7 } Weights & 0.036 & 0.052 & 0.250 & 0.435 & 0.141 & 0.086 & \\
\hline A1 & 0.212 & 0.332 & 0.332 & 0.644 & 0.332 & 0.414 & 0.471 \\
A2 & 0.212 & 0.803 & 0.414 & 0.644 & 0.644 & 0.644 & 0.579 \\
A3 & 0.108 & 0.332 & 0.332 & 0.212 & 0.212 & 0.332 & 0.255 \\
A4 & 0.332 & 0.332 & 0.644 & 0.108 & 0.108 & 0.516 & 0.297 \\
A5 & 0.803 & 0.414 & 0.803 & 0.332 & 0.332 & 0.644 & 0.498
\end{tabular}

Table 7. Aggregated evaluations of locations, weights and the final scores of the alternatives.

According to the results shown in Table 7, A2 (Prof. Dr. Aykut Barka Park) is the most appropriate place for field hospital in Besiktas municipality. It is followed by A5 (Yildiz Park) and A1 (Beşiktaş Sanatçılar Park).

\section{Limitations}

We have some limitation in this study about the number of bed in a field hospital. Because the land in Istanbul has too many slap and we have to constitute several field hospital in small area in smooth land. For analyzing we connive the slap of land and analyze alternative by Distance from Arterial Routes, Travel Time area to access existing hospitals; Environmental pollution, and Population Density in GIS analyze system.

\section{Conclusions}

This study provides decision makers with a model to determine optimal field hospital location(s) by combining AHP and GIS. The roles of AHP and GIS in determining optimal locations explain, criteria, and case study results for finding the optimal field hospital locations in Besiktas, Istanbul, Turkey include.

The interaction with AHP and GIS combines decision support methodology with powerful visualization and analyzing capabilities which should considerably facilitate finding optimal locations of field hospital and this process improves the decision-making in emergency management. 
IJAHP Article: Mu, Saaty/A Style Guide for Paper Proposals To Be Submitted to the International Symposium of the Analytic Hierarchy Process 2014, Washington D.C., U.S.A.

In the literature review, there are some studies on AHP and GIS interaction. We consider on the intersection of these three subjects of AHP, GIS and emergency management. In this case study correct criteria and criteria weights need to have correct analysis. In this case, we use the GIS visualization to improve the decision making process and use better decision resources for analyzing. By making best decision we can use resources more effectively and can decrease the loss of human and property.

\section{Key References}

List here only those 3 to 5 references that are key for the study at hand. As an example:

Mohammad H. Vahidnia, Ali A. Alesheikh, Abbas Alimohammadi. (2009). Hospital site selection using fuzzy AHP and its derivatives. Journal of Environmental Management, 90, 3048-3056.

Saaty, T.L. (1980). The Analytic Hierarchy Process: Planning, Priority Setting, Resource Allocation. McGraw-Hill, New York, NY.

Marjan Javadiana, Hanieh Shamskooshkia, Mostafa Momenia (2011). Application of sustainable urban development in environmental suitability analysis of educational land use by using AHP and GIS in Tehran. Procedia Engineering, 21, 72-80.

T. Erden and M. Z. Cos sun. (2010). Multi-criteria site selection for fire services: the interaction with analytic hierarchy process and geographic information systems. Natural Hazards and Earth System Sciences, 10, 2127-2134. 